\title{
SCIDoC
}

International Journal of Dentistry and Oral Science (IJDOS)

ISSN: 2377-8075

\section{Modified Serial Extraction in Patient with Sever Crowding: A Case Report}

Thamer E Alzahrani*

Department of Orthodontic and Dentofacial Orthopedics, Faculty of Dentistry, Taif University, Taif, Saudi Arabia.

\section{Abstract}

Serial extraction treatment is interceptive treatment to resolve arch length / tooth mass discrepancy. It follows serial extraction of primary teeth to facilitate the eruption of the 1st premolar and then extract it. In our case we present modification for the serial extraction treatmentby extraction of the 2 nd premolars instead of the $1 \mathrm{rs}$ premolars. We believe that this is good modification to the serial extraction patterns, especially in cases with abnormal eruption sequence.

Keywords: Interceptive Orthodontic; Serial Extraction; Sever Crowding.

\section{Introduction}

Interceptive treatment defined in 1982 by Richardson, he states that it mean the prompt treatment ofunfavourable features of a developing occlusion that may makethe difference between achieving a satisfactory result by simple mechanics later, thus reducing overall treatment time and providing better stability and functional and aesthetic results. [1]

The term serial extraction is an example of an interceptive treatment. It is the correctly timed and planned removal of deciduous and permanent teeth in mixed dentition cases with sever crowding to allow the unerupted teeth to guide themselves into better positions and reduce the long period of fixed appliance therapy. [2]

The classical pattern of serial extraction as the following [3]:

- Stage I: (Extraction of all deciduous lateral incisors). To help in the alignment of the central incisors.

- Stage II: (Extraction of all deciduous canines after 7-8 months). For alignment of the lateral incisors

- Stage III: (Extraction of all deciduous first molars). To stimulate eruption of 1 st premolars

- Stage IV: (Extraction of all first premolars after 7-8 months). This stage provides the space needed for canines and stimulates their eruption.

The usual eruption pattern is the eruption of the $4 \mathrm{~s}$ (1st premo- lar) a head of the $5 \mathrm{~s}$ (2nd premolars)[4]. however, in our case which will be presented below the mandibular 2nd premolars erupt ahead of the 1 st premolars.

\section{Case Report}

A twelve-year-old Saudi female patient had a chief complaint of an irregular teeth came to the orthodontic clinics in Faculty of dentistry, king Abdelaziz University. Upon extra oral examination the patient has mesofacial face type , fairly symmetrical face and competent lips. The profile is slightly convex (Figure 1). Upon intra-oral examination (figure 2) she had severely inflamed gingiva, tooth no. 12 and 22 in cross-bite, tooth no. 15 in buccal cross bite, thin attached gingiva related to tooth no. 41 and Stainlesssteel crown on tooth no. 46. She has the following permanent dentition:

- Upper right: 1st molar, 1st and 2nd premolar central and lateral incisors.

- Upper left: 1st molar, central and lateral incisors.

- Lower left: 1st molar, central and lateral incisors.

- Lower right: 1st molar, 2nd premolar central and lateral incisors.

The crowding had been measured in the dental model (figure 3) and it showed the following:

- $9 \mathrm{~mm}$ crowding in upper arch.

- 8 mm crowding in lower arch.

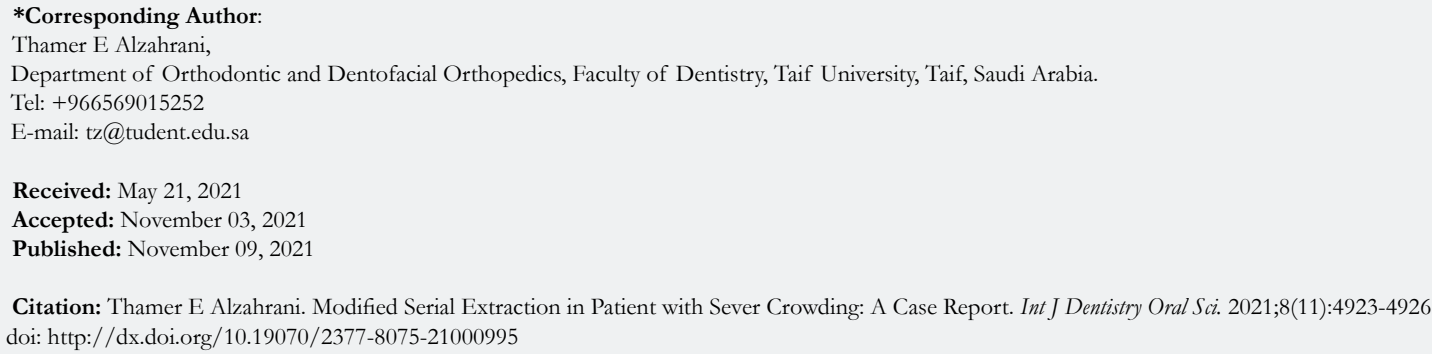

Copyright: Thamer E Alzahrani ${ }^{\odot} 2021$. This is an open-access article distributed under the terms of the Creative Commons Attribution License, which permits unrestricted use, distribution and reproduction in any medium, provided the original author and source are credited. 
- Class I molar in the right side.

- Class I molar in the left side.

The panoramic radiographs and cephalometric radiograph are presented in (figure 4, 5)

A summary for the cephalometric analysis is the following:

- Class I skeletal relationship.

- Hyperdivergent mandible.

- Retroclined upper and lower incisors

The treatment was done as modified serial extraction, (extraction of the single permanent premolar in each quadrant to allow for eruption of the canine and resolve the space deficiency). First, we extract the primary teeth $(53,63,64,65,74)$ and we also extracted the permanent tooth number 14 then we did band and bond $2 * 4$ appliance to correct the anterior cross bite. (Figure 5) show the photograph progress at the start of the treatment, then we extract tooth no. 45(the lower right 2 nd premolar erupts ahead of the 1stpremolar) and(Figure 6) shows the radiograph after the extraction of the lower right premolar.

When the upper left 1st premolar erupted (tooth number 24), we extracted it, (figure 7) show the progress radiograph. (Figure 8) show the progress photographs after the extraction of all upper 1 st premolar and lower 2 ndpremolars, and the panoramic radiograph is shown in (figure 9).

After the eruption of the lower first premolars and the upper canines, we bonded them to align them with the arch (figure 10).

(Figure 11,12,13) show the final records. While (Figure 14) show pre and post smile and frontal photographs for the patient.

This case had been treated successfully with a modified serial extraction plane because the different in the eruption sequence of the patients in the lower arch.

\section{Discussion}

The normal eruption time of the succedaneous teeth as the following, for the upper arch: the central incisors erupt around the age 7-9 years, lateral incisors 7-9 years, canines $11-12$ years, $1 \mathrm{st}$ premolar 10-11 years, 2nd premolar 10-12 years old. So as summary the sequence as the following: $1,2,4,5,3$. While in the lower arch the eruption the timing of the eruption is the following: central incisors 6-8 years, lateral incisors 6-8 years, canine 9-10 years, 1st premolar 10-12 years, 2nd premolar 11-12 years old. So as summary the sequence as the following: $1,2,3,4,5$. [4]
Figure 1. Pretreatment extra oral photographs.

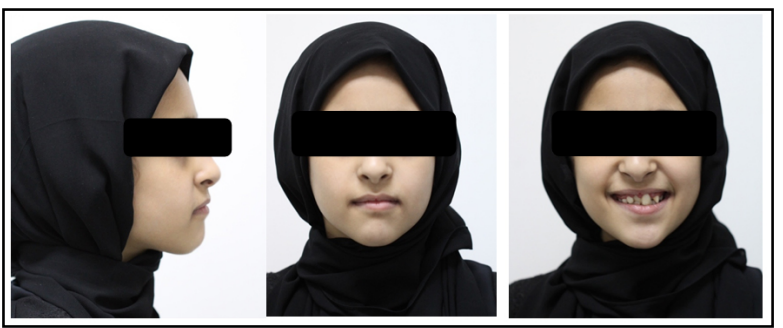

Figure 3. Pretreatment dental models.

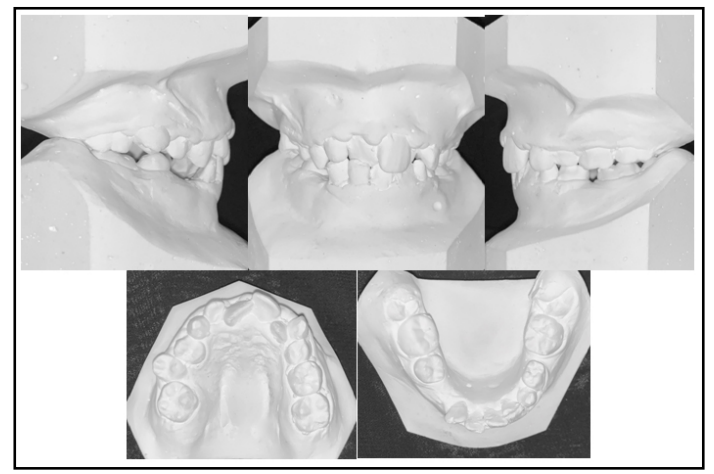

Figure 5. Progress 1 Photographs.

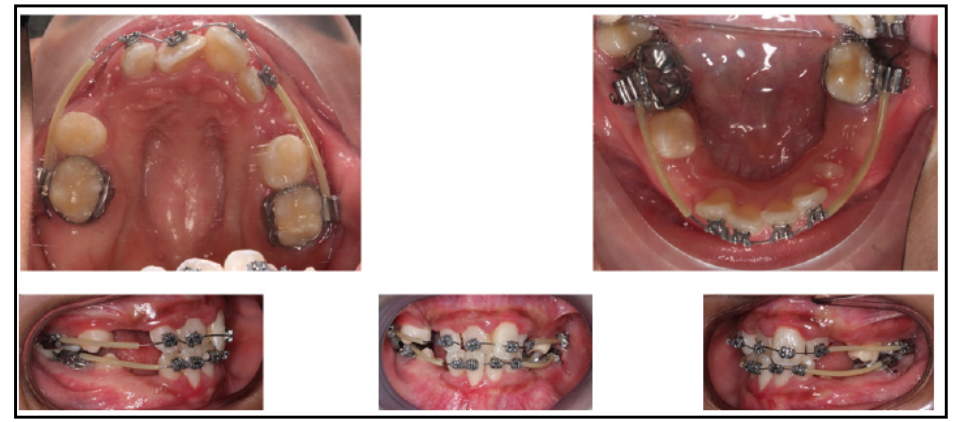

Figure 2. Pretreatment intra oral photographs.

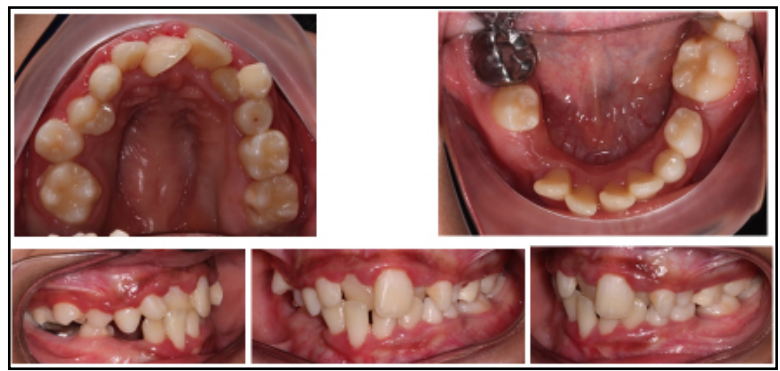

Figure 4. Pretreatment Panoramic Radiograph.

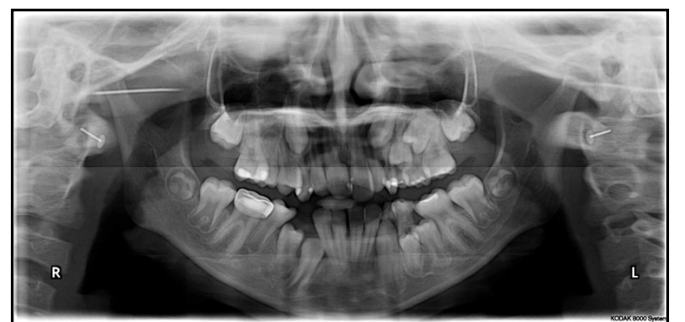

Figure 4. Pretreatment Lateral Cephalometric Radiograph.

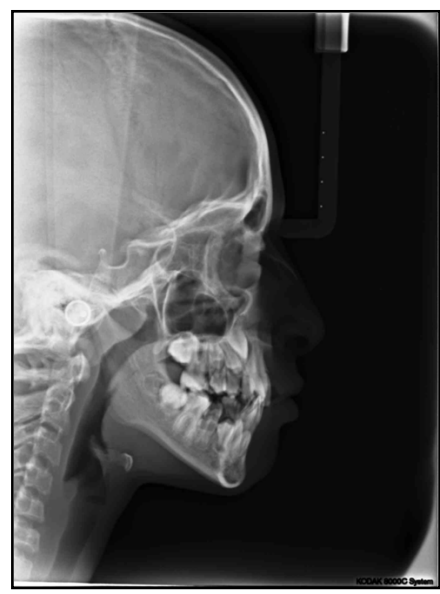


Figure 6. Progress 1 radiograph.

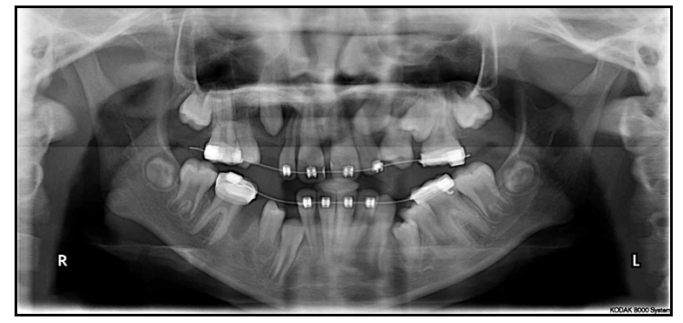

Figure 8. Progress 2 photographs.

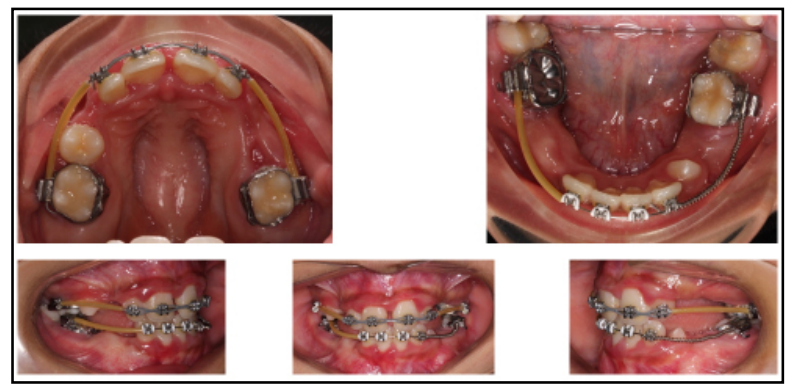

Figure 10. Progress 3 photographs.

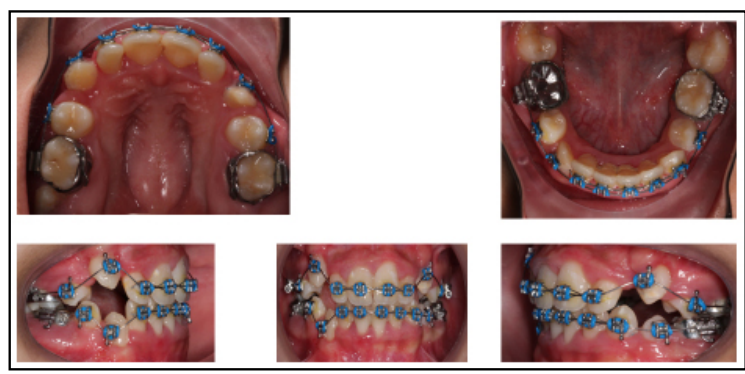

Figure 12. Final panoramic radiograph.

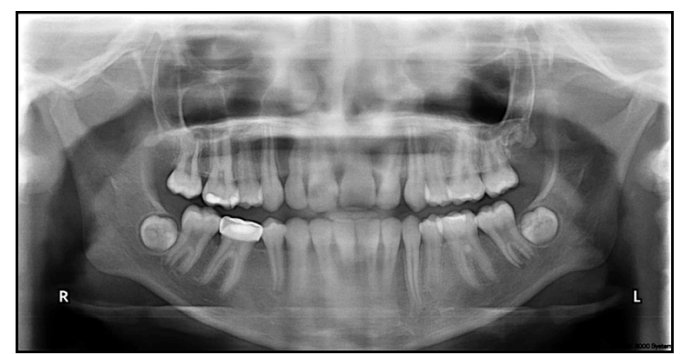

Figure 7. Progress 2 radiograph.

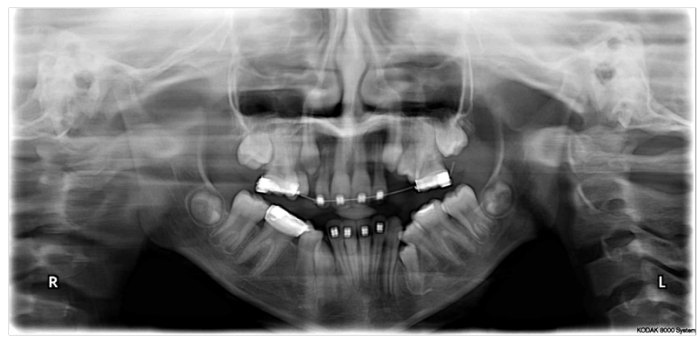

Figure 9. Progress 3 radiograph.

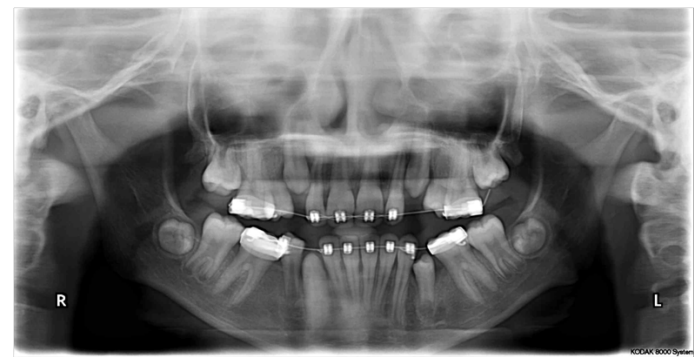

Figure 11. Final Photographs.

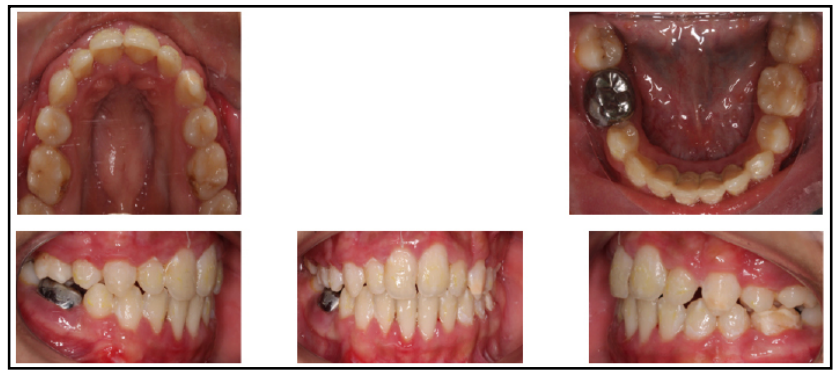

Figure 13. Final cephalometric radiograph.

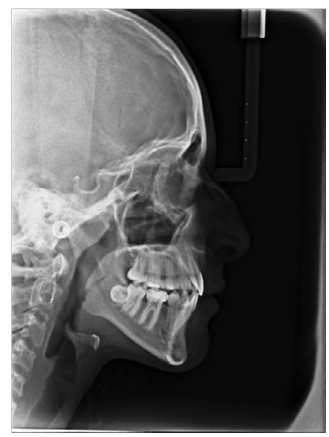

Figure 14. Pre And Post Frontal Photograph And Smile.

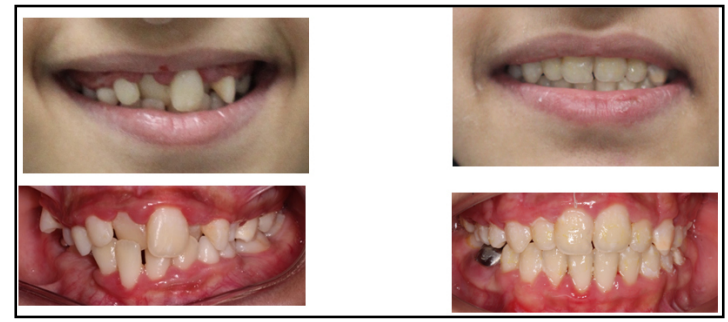

There are many benefits in the literature for the early treatment of sever crowding by serial extraction, it includes the following : improvement of self-esteem, improve the oral hygiene and better chewing ability. $[5,6]$

Some treatment possibility for the sever crowding in mixed dentition, is expansion of the arch. However, the stability was poor and the irregularity index was $6 \mathrm{~mm}$ after 7.5 years follow up. [7] In the other hand, the long term stability with one premolar extraction was higher and the irregularity index was $4.3 \mathrm{~mm}$ [8], $3.5 \mathrm{~mm}$ [9] and $3 \mathrm{~mm} \mathrm{[10]} \mathrm{respectively.}$

Our treatment might be more appropriate to called it (Sequential Extraction) instead of serial extraction for two reasons. First it doesn't follow the same extraction pattern of classical serial extraction.Second, in serial extraction the aim is to allow the physiological migration of the teeth into better position, then it followed by active phase with fixed appliance. However, we started the fixed appliance treatment in this case early due to the anterior cross bite. 
There are some advantages for second premolars extraction instead of the first premolars. One of the advantages is the limitation of the lingual tipping of the mandibular incisors, which will cause minimum increase of curve of Spee and over bite, further more maintaining the position of the lower incisors reduce the flattering of the facial profile [11].

\section{Conclusion}

Serial extraction treatment in this patient had been successful in resolving the arch length/tooth mass discrepancy, resolve the anterior cross bite and prevented impaction of the canines. The second premolar extraction can be considered for serial extraction cases especially in cases with irregular eruption sequence or expected impaction of the 2 nd premolars.

\section{Acknowledgment}

I would like to thank Prof. Khalid Zawawi for his continuous support throughout the treatment.

\section{References}

[1]. Richardson A. Interceptive orthodontics in general dental practice. Part I-
-Early interceptive treatment. Br Dent J. 1982 Feb;152(3):85-9. Pubmed PMID: 6949600

[2]. Mahajan N, Bansal S, Goyal P. Interceptive Orthodontics: A Review. JIDA J Indian Dent Assoc. 2014;8(7).

[3]. Naragond A, Kenganal-Parekh SS, Fields HW. Serial extractions-A review. IOSR J Dent Med Sci. 2012;3:40-473.

[4]. Scott J \&symons N. introduction to dental anatomy. 9th editio. 1990.

[5]. Yoshihara T, Matsumoto Y, Suzuki J, Sato N, Oguchi H. Effect of serial extraction alone on crowding: relationships between tooth width, arch length, and crowding. Am J Orthod Dentofac Orthop Off Publ Am Assoc Orthod its Const Soc Am Board Orthod. 1999 Dec;116(6):691-6. Pubmed PMID: 10587605

[6]. Dale JG. Serial extraction ... nobody does that anymore! Am J Orthod Dentofac Orthop Off Publ Am Assoc Orthod its Const Soc Am Board Orthod. 2000 May;117(5):564-6. Pubmed PMID:10799116.

[7]. Little RM, Riedel RA, Stein A. Mandibular arch length increase during the mixed dentition: postretention evaluation of stability and relapse. Am J Orthod Dentofac Orthop Off Publ Am Assoc Orthod its Const Soc Am Board Orthod. 1990 May;97(5):393-404. Pubmed PMID:2333853.

[8]. Little RM, Riedel RA, Engst ED. Serial extraction of first premolars--postretention evaluation of stability and relapse. Angle Orthod. 1990;60(4):25562. Pubmed PMID:2256562.

[9]. McReynolds DC, Little RM. Mandibular second premolar extraction--postretention evaluation of stability and relapse. Angle Orthod. 1991;61(2):133-44. Pubmed PMID:2064071.

[10]. Haruki T, Little RM. Early versus late treatment of crowded first premolar extraction cases: postretention evaluation of stability and relapse. Angle Orthod. 1998 Feb;68(1):61-8. Pubmed PMID:9503136.

[11]. Joondeph DR, Riedel RA. Second premolar serial extraction. Am J Orthod. 1976;69(2):169-84. Pubmed PMID:1061507. 